\section{Placebos and the Philosophy of Medicine}

Howard Brody, MD, PhD, University of Chicago Press, 1980, I64 pp (No price)

Every doctor knows, or thinks he knows, what a placebo is and what effects it may have. Dr Brody has cured me of this misapprehension but after reading his book my concepts are not much clearer. This is my fault rather than his. I just find philosophical arguments difficult to follow. After I have grappled with each sentence I find that I have forgotten the previous one so that I get lost. This is not a book for those who, like me, have predominantly objective and visual concepts of physical and mental processes.

Dr Brody starts by outlining the need for a coherent philosophy of the relationship of mind and body and the ethical aspects of medical interference in their activities. He reviews the literature on placebos, showing how confused, and even contradictory, medical theories have been about their nature and action. This leads on to an attempt to achieve definitions of 'placebo' and 'placebo effect' which can bear philosophical weight, which is illustrated by clinical vignettes of seven different circumstances of placebo effect. He dismisses existing definitions as too imprecise or too vague, and proposes a clearer more precise definition of placebo as 'a form of medical therapy, or an intervention designed to simulate medical therapy, that at the time of its use is believed not to be a specific therapy for the condition for which it is offered and that is used either for its psychological effect or to eliminate observer bias in an experimental setting'.

The going gets harder as he reviews traditional concepts of the mind-body relationship rejecting most of them, ending up with a position called 'eliminative materialism' and going on to present and justify in some detail, little of which I could follow, a 'Theory of the Person'. This leads on to a review of 'Ethical Problems in Placebo Use', concluding that the arguments which favour their use 'are notable for the cavalier attitude which they display towards patient deception' and pleading for 'eliciting a placebo effect by non-deceptive means from a utilitarian standpoint'. (We are lucky in not having to consider problems of our patients having to pay as much for placebos as for expensive drugs.) He makes suggestions for further research in this field of medicine and discusses the practical use of placebos, dismissing four commonly held medical myths about their use and recommending more logical and co-operative ways of dealing with the sorts of conditions for which doctors normally use placebos. $\mathrm{He}$ finally concludes: 'Properly developed, a study of placebo effect can do much to highlight the centrality of the whole person both to the philosophy of medicine and to medical practice'.

I doubt whether this book, short as it is, will be widely read or have much impact on medical practice, for few doctors have learned to wade through intense philosophical reasoning. But if they only skim through it they will come to realise that the use of placebos is not the easy matter that their simple chemistry might suggest.

CHARLES FLETCHER

\section{Talking with Patients-A Teaching Approach}

The Nuffield Provincial Hospitals Trust, $197955 \mathrm{pp}$, 5op.

If a survey were carried out asking doctors to rate their own ability to communicate with patients, one suspects that the results would be similar to those of a survey which showed that over 80 per cent of drivers regarded themselves as 'above average' in driving skill. One might also find that some of the doctors who had doubts about their performance in consultation might in fact be good communicators. $\overrightarrow{\vec{H}}$

The pitfalls of consultation org succinctly explored in Talking ith Patients-A Teaching Approac booklet compiled by a Nuffield Working Party on Communications with Patients, chaired by Professor Sir John Walton, Dean of Medicine and Professor of Neurology at Ghe University of Newcastle-upon-Tyne. The booklet can be ingested in ene sitting but provides much food 앙 thought. The clinical interview the exposition are followed by three useful appendices and a valuesle annotated bibliography by Professor Charles Fletcher.

In the section on the intervie it states 'In the course of the clin years, students' interviewing s/1ls may actually deteriorate, rather tan improve. Before they have acquaed much medical knowledge, they tind to listen to what patients have to 3 ell them and to express interest and concern about their psychologal reactions to their illness and their social difficulties. When they läve learned more about disease, they tend to make a quick provisional diagnosis and to confine the patignt during the rest of the interviews to answering questions which appear relevant to this diagnosis' 윽 a mistake we have all made.

Introducing 'The Exposition' कhe authors comment 'Despite the difficulties which many students findsin acquiring a good interviewing technique, many doctors do becqbie skilled interviewers. But overcome the difficulties of $8 x-$ plaining the necessity of treatment; of persuading him to change way of life; of breaking bad ne्धws and perhaps confessing the adequacy of therapy, while at Dhe same time retaining his confidenळe'. Ways of improving the exposition include better verbal information, considering what the patient werits to know, written instructions, tope recordings of information, feedlo@ ck on patients' intake of informatinn, 
avoidance of jargon, the doctor's attitude, careful supervision, gadgets such as pill boxes as an aid to memory, enabling patients to express their anxieties and avoidance of conflicting information. The attitude of the doctor appears to be paramount. 'The sympathetic doctor's instructions and explanations are followed, understood and remembered better than those of a doctor who appears cold and uninterested'.

In all, this is a thought-provoking and challenging booklet which will be a great help to all who have to teach medical students and are conscious of their own shortcomings in their dealings with patients. One small quibble is with the use of the word 'compliance' which seems now to have become established in the literature of doctor-patient communication. It is surely more applicable to what a sergeant major tries to achieve with raw recruits. When we are trying to help patients perhaps 'co-operation' would be more appropriate

The illustrations drawn by John Moll are both apt and funny.

P A ANDERSEN

\section{Medical Responsibility: \\ Paternalism, Informed Consent and Euthanasia}

Wade L Robison and Michael S Prichard (Eds).

Humana Press, 1979, 240 pp. \$19.50.

Most of the thirteen papers in this collection were originally presented at a conference on Philosophy, Law and Medicine held in Michigan in 1976. Several have already been published elsewhere. The main topics are: the definition and justification of paternalism, the ethics of experiments on human subjects, non-therapeutic fetal experimentation, and euthanasia. In spite of the book's origins the editors do not regard it simply as another volume of conference proceedings. They intend it as an introduction to medical ethics which will display the common moral concerns underlying apparently diverse problems. Some of the papers, notably Childress's 'Paternalism and Health Care' and Rachels' 'Euthanasia, Killing and Letting Die', would indeed constitute excellent introductions to their topics. Others, for example Gert and Culver's 'The Justification of Paternalism', serm to demand too much philosophical sophistication for this purpose.

With one exception (Beauchamp's reply to Rachels), the papers are entirely independent of one another, so there is little sense of debate among the contributors. Equally the editors make no serious attempt to show how discussion of the different topics might be linked together. This is a pity, since it would be easy to draw instructive and fruitful parallels. For example, the papers on paternalism and experimentation on human subjects naturally concentrate on questions about selfdetermination. Is informed consent always required? What does it mean? What are the practical difficulties in ensuring that subjects really do consent? All these questions need also to be raised about proposals to legitimise voluntary euthanasia.

But the papers on euthanasia included in this volume say nothing about these questions. Instead they discuss the difference, if any, between killing and letting die and the definition of death. In themselves these papers are excellent but their inclusion in the present volume does not help the reader to see the common moral concerns underlying diverse problems.

Most of the contributors appear to be professional philosophers and this gives the volume as a whole a certain one-sideness. Although all the authors have conscientiously illustrated their points with medical examples one sometimes feels that the argument may be getting a little remote from the realities of medical practice.

Thus taken as a whole the volume does not fulfil its editors' ambitions. On the other hand most of the individual contributions do have something worthwhile to say. It is a volume which anyone working in medical ethics will need to consult.

R F STALLEY

Ethical issues in death and dying

Tom L Beauchamp and Seymour Perlin (Eds).

Prentice-Hall Inc, 1978, 368 pages, $£ 6.85$.

This book is divided into five sections called respectively: The Definition and Determination of Death; Suicide; Rights of the Dying Patient; Euthanasia and Natural Death; and The Significance of Life and Death. A short Introduction by the Editors sets the scene for each section and is followed by a number of articles or 'readings', some presumably written for this volume and others taken from the literature, past and present. They are arranged in the form of a debate with brief linking summaries and opposing viewpoints are juxtaposed. This reviewer found the format helpful as through this type of analysis and argument the danger of over-simplification of what are very complex ethical issues is stressed. A good example is the Harvard Definition of Brain Death (or irreversible coma) which at the time of its introduction in 1968 was considered to be unambiguous and straightforward, yet as Veatch and Jonas, among others, indicate, there are problems with this definition and it has required modification in subsequent years. Many are still unhappy with it and its implications.

I liked the section on the 'Rights of the Dying Patient' and I hope that many present and future clinicians will study it. Widely divergent views are expressed on the conflict that may occur between what a doctor views as his professional obligation to treat a patient and the patient's right to refuse treatment. Legally, 'there is the fear that any exception to the sanctity of life cannot but cheapen it' (Hegland), yet 'Human dignity is enhanced by permitting the individual to determine for himself what beliefs are worth dying for'. (Cantor). The section on 'Euthanasia', that most contentious of contemporary issues, includes the familiar arguments about 'active' and 'passive' euthanasia. (Almost inevitably there is a review of some of the issues in the Quinlan case.)

Discussion on the particularly poignant problem of defective newborn infants concentrates on the legal issues involved. Robertson and Fost point out the dangers of physicians claiming the right to act in defiance or ignorance of existing laws. They suggest that we need 'either a set of authoritative criteria describing the limited circumstances in which ordinary care may be withheld from defective newborn infants or a process of decision-making which minimises the risk of abuses or mistakes'. Such processes have been developed but are not enough in themselves without some equivalent change in the law. Fear of the 